\title{
Cost Reduction of Fluid Catalytic Cracking Unit in Kaduna Refining and Petrochemical Company using Pinch Technology
}

Department of Chemical Engineering, Ahmadu Bello University, Zaria, Nigeria.

ABSTRACT: Pinch technology is one of the most powerful methodologies of process integration that allows industries to increase their profitability through reductions in energy, water and raw materials consumption. In this study, reduction in the total annual cost of heat exchanger network (HEN) of Fluid Catalytic Cracking (FCC) unit in Kaduna Refining and Petrochemical Company (KRPC), Kaduna was determined. With the help of pinch technology, the reduction was achieved by first determining optimum minimum temperature difference by trading off energy cost and capital cost targets as a function of minimum temperature difference. Thereafter, the total annual cost obtained at the optimum minimum temperature difference was compared with total annual cost of existing design. The results of the analysis showed that the optimum minimum temperature difference was $12^{\circ} \mathrm{C}$, the total annual costs of the existing design and the optimum-minimum-temperature-difference based cost were $\$ 8.7$ and $\$ 7.1$ Million respectively. This amounted to percentage reduction in the total annual cost of $18.4 \%$ which means that about $\$ 1.6$ Million would been saved annually using the optimum minimum temperature difference to design the HEN of the FCC unit.

KEYWORDS: Pinch technology, FCC unit, Cost targeting, Area targeting, Trade-off

[Received December 20, 2019, Revised June 3, 2020, Accepted July 24, 2020]

Print ISSN: 0189-9546 | Online ISSN: 2437-2110

\section{INTRODUCTION}

The severe competition for limited energy in everyday life, technology and development calls for its maximum utilization and this is more so in chemical industries where huge amount of energy is needed. In petroleum and petroleum industries, fluid catalytic cracking (FCC) unit, which is widely regarded as the heart of any refinery, is one of the most energyconsuming units. This energy is usually provided using various utilities like furnace heaters, steam, water and air. However, the consumption of these external utilities can be drastically minimized by using pinch technology to maximize the use of energy available in process streams (Anna, 2011). Pinch technology is the most powerful and widely used process integration methodologies in industries to increase profitability. This can be achieved through reductions in energy (Leni et al., 2015; Rathjens et al., 2016; Souza et al., 2016; Akgun and Ozcelik, 2017; Chang et al., 2017; Aguitoni et al., 2018; Rathjens and Fieg, 2018).

Similarly, increased profitability can also be achieved through reduction in waste generation, water and raw materials consumption (Sasikala, 2017); and reduction in greenhouse gas emission and environmental pollution control ( $\mathrm{Li}$ et al., 2016; Abdul Aziz et al., 2017; Manan et al., 2017; Venkatesh, 2019). The technology is based on thermodynamic principles that provides a systematic approach for energy saving with a wide range of applications in many chemical processes (Yoro et al., 2019). Although the application of this technology is *Corresponding author: abubakara@abu.edu.ng most pronounced in oil and gas industries (Marton et al., 2017; Akpa et al., 2018; Ulyev et al., 2018), its use can be found in bioprocessing industry (Anastasovski et al., 2107), sugar production industry (Barambu et al., 2017), brewing industry (Tibasiima and Okullo, 2017) and cement industry (Verma and Kumar, 2017). It has also been used in addressing project selection problem (Pritam et al., 2017).

Typical industrial processes like the FCC units comprise several numbers of hot and cold process streams most of which demand cooling and heating respectively. For this reason, part of the excess heat of the hot process streams is often recovered using heat exchangers to satisfy part of the heat need of the cold process streams. Thereafter, external heaters and coolers are used to achieve the final temperature demand of the process streams. In other words, there must be proper interconnections of hot and cold process streams using heat exchangers to achieve the desire heat recovery and this is where pinch technology comes to play. The most fascinating aspect of the pinch analysis is the ease with which targets can be set even prior to the actual design of the heat exchanger networks. Such targets include heat exchanger area, utility energy (or operating) cost and heat exchanger capital cost targets. All these targets depend on the value of the driving force for the heat flow that is known as the minimum temperature difference $\left(\Delta T_{M I N}\right)$. Essentially, pinch analysis involves the location of pinch point, which is the temperature level in the process streams where the $\Delta T_{M I N}$ is observed (Rokni, 2016).

doi: http://dx.doi.org/10.4314/njtd.v17i3.5 
Several works involving the use of pinch analysis for heat and mass integration of industrial processes have been reported in literatures. Some of the earliest contributors include Linnhoff and Hindmarsh (1983) who used pinch method to design heat exchanger networks, and Gunderson and Naess (1988) who conducted an industrial review on the synthesis of optimal cost heat exchanger network. Other related works include determination of an explicit solution for thermal calculation and synthesis of superstructure heat exchanger networks (Dezhen et al., 2007) and conduction of detailed capital and total cost targets for mass exchanger networks (Hallale and Fraser, 2000). Similarly, Lukman et al. (2015) carried out analysis of heat exchanger networks for minimum total annual cost using pinch analysis and Lukman et al. (2016) carried out an evaluation of total annual costs of heat exchanger networks using modified pinch analysis.

In this study, the focus was to determine reduction in the total annual cost of the FCC unit of KRPC, Kaduna if pinch technology would have been applied as against the existing design. This was achieved by determining the optimum temperature difference using pinch analysis that guarantees the best trade-off in the energy (or operating) cost and capital cost targets.

\section{MATERIALS AND METHODS}

\section{A. Materials}

The material required for this work was the operating manual of the FCC unit that contains the thermal data. However, these data (as presented in Tables 1 and 2) had already been extracted from the operating manual during the course of our previous work (Olakunle and Abubakar, 2011).

Table 1 presents the thermal data of the existing process streams while Table 2 presents the thermal data of the existing utility streams in the FCC unit. There were nineteen process streams comprising fourteen hot streams and five cold streams. For the utility streams, there were two types of cold utilities: cooling water $(\mathrm{CW})$ and cooling air (CA), and there were also two types of hot utilities: furnace and steam. Four hot process streams were cooled by both water and air, six were cooled by only water, three were cooled by only air and one was not cooled. Similarly, one cold process stream was heated by furnace; another one was heated by steam while the remaining three were not heated.

\section{B. Methods}

\section{1.) Estimation of energy (or operating) cost targeting}

First, the range of initial $\Delta T_{M I N}$ was selected based on the information from literature as it strongly depends on the type of chemical industry under consideration. For petrochemical industries in general, the $\Delta T_{M I N}$ is expected not to go beyond $40^{\circ} \mathrm{C}$ (Adejoh et al., 2013; Lukman et al., 2016). Hence, the range of initial $\Delta T_{M I N}$ was selected to vary from 5 to $40^{\circ} \mathrm{C}$ and a step size of $5^{\circ} \mathrm{C}$ of this range was adopted. Then, the combined composite curves for each value of the $\Delta T_{M I N}$ were constructed using the procedure detailed by Rokni (2016). They are actual temperature - heat load curves and consist of hot (i.e. profiles of heat availability or hot streams in the
Table 1: Thermal data of the process streams in FCC unit (Olakunle and Abubakar, 2011).

\begin{tabular}{|c|c|c|c|c|c|c|}
\hline \multicolumn{3}{|c|}{ Process Stream } & \multirow{2}{*}{$\begin{array}{l}\text { Heat } \\
\text { Duty } \\
\text { (MW) }\end{array}$} & \multicolumn{2}{|c|}{$\begin{array}{c}\text { Actual } \\
\text { Temp. }\left({ }^{\circ} \mathrm{C}\right)\end{array}$} & \multirow[t]{2}{*}{$\begin{array}{c}\mathrm{CP} * \\
\left(\mathrm{MW} /{ }^{\circ} \mathrm{C}\right.\end{array}$} \\
\hline Name & Type & No. & & $\mathbf{T}_{\mathrm{S}}$ & $\mathbf{T}_{\mathrm{T}}$ & \\
\hline Column Overhead & Hot & H1 & 19.87 & 135 & 36 & 0.200 \\
\hline Heavy Naphtha & Hot & $\mathrm{H} 2$ & 8.22 & 169 & 33 & 0.060 \\
\hline Light Cycle Oil & Hot & $\mathrm{H} 3$ & 2.21 & 215 & 60 & 0.014 \\
\hline $\begin{array}{l}\text { Heavy Cycle Oil } \\
\text { Pump Around }\end{array}$ & Hot & $\mathrm{H} 4$ & 6.66 & 271 & 186 & 0.078 \\
\hline $\begin{array}{l}\text { Column Bottom } \\
\text { Pump Around }\end{array}$ & Hot & H5 & 13.10 & 350 & 232 & 0.111 \\
\hline $\begin{array}{l}\text { Column Bottom } \\
\text { Product }\end{array}$ & Hot & H6 & 1.04 & 334 & 80 & 0.004 \\
\hline $\begin{array}{l}\text { Gas Compression } \\
\text { Interstage }\end{array}$ & Hot & $\mathrm{H} 7$ & 1.93 & 73 & 36 & 0.052 \\
\hline $\begin{array}{l}\text { Gas Compression } \\
\text { Discharge }\end{array}$ & Hot & $\mathrm{H} 8$ & 3.12 & 69 & 36 & 0.095 \\
\hline Gasoline Product & Hot & H9 & 6.15 & 187 & 40 & 0.042 \\
\hline $\begin{array}{l}\text { Sour Water Stripper } \\
\text { Bottom }\end{array}$ & Hot & $\mathrm{H} 10$ & 1.74 & 135 & 40 & 0.018 \\
\hline $\mathrm{C}_{3} / \mathrm{C}_{4}$ LPG Product & Hot & H11 & 0.18 & 54 & 40 & 0.013 \\
\hline Semi Rich Oil & Hot & $\mathrm{H} 12$ & 0.06 & 41 & 33 & 0.008 \\
\hline $\begin{array}{l}\text { Debutanizer } \\
\text { Overhead }\end{array}$ & Hot & $\mathrm{H} 13$ & 5.48 & 67 & 53 & 0.391 \\
\hline $\begin{array}{l}\text { Sour Water Stripper } \\
\text { Overhead }\end{array}$ & Hot & $\mathrm{H} 14$ & 3.34 & 126 & 93 & 0.101 \\
\hline Fresh Feed & Cold & $\mathrm{C} 1$ & 24.06 & 70 & 358 & 0.084 \\
\hline $\begin{array}{l}\text { Mid Stripper Pump } \\
\text { Around }\end{array}$ & Cold & $\mathrm{C} 2$ & 4.82 & 88 & 111 & 0.210 \\
\hline $\begin{array}{l}\text { Mid Debutanizer } \\
\text { Pump Around }\end{array}$ & Cold & $\mathrm{C} 3$ & 5.74 & 105 & 187 & 0.070 \\
\hline Debutanizer Feed & Cold & $\mathrm{C} 4$ & 3.74 & 110 & 220 & 0.034 \\
\hline Sour Water & Cold & $\mathrm{C} 5$ & 1.10 & 53 & 70 & 0.065 \\
\hline
\end{tabular}

Table 2: Thermal data of the utility streams in FCC unit (Olakunle and Abubakar, 2011)

\begin{tabular}{|c|c|c|c|}
\hline \multirow[t]{3}{*}{ Process Stream } & \multirow{2}{*}{\multicolumn{2}{|c|}{ Heat Duty (MW) }} & \multirow[t]{3}{*}{ Total (MW) } \\
\hline & & & \\
\hline & $\begin{array}{l}\text { Cooling } \\
\text { Water } \\
\text { (CW) }\end{array}$ & $\begin{array}{l}\text { Cooling } \\
\text { Air } \\
\text { (CA) }\end{array}$ & \\
\hline Column Overhead & 1.73 & 18.14 & 19.87 \\
\hline Heavy Naphtha & 0.61 & - & 0.61 \\
\hline Light Cycle Oil & - & 0.54 & 0.54 \\
\hline Column Bottom Pump Around & 3.46 & - & 3.46 \\
\hline Column Bottom Product & 0.44 & 0.06 & 0.50 \\
\hline Gas Compressor Interstage & 1.93 & - & 1.93 \\
\hline Gas Compressor Discharge & 1.93 & 1.19 & 3.12 \\
\hline Gasoline Product & 1.02 & 3.59 & 4.61 \\
\hline Sour Water Stripper Bottom & 0.64 & - & 0.64 \\
\hline C3/C4 LPG Product & 0.18 & - & 0.18 \\
\hline Semi Rich Oil & 0.06 & - & 0.06 \\
\hline Debutanizer Overhead & - & 5.48 & 5.48 \\
\hline Sour Water Stripper Overhead & - & 3.34 & 3.34 \\
\hline \multirow[t]{3}{*}{ Total } & 12.00 & 32.88 & 44.88 \\
\hline & \multicolumn{2}{|c|}{ Hot Utility } & \\
\hline & Furnace & Steam & \\
\hline Fresh Feed & 9.04 & - & 9.04 \\
\hline Debutanizer Overhead & - & 2.20 & 2.20 \\
\hline Total & 9.04 & 2.20 & 11.24 \\
\hline
\end{tabular}

the process) and cold (i.e. heat demand or cold streams in the process) composite curves. The construction of each curve was carried out by adopting 'Problem Table Method'. In this method, the respective streams' actual temperatures (both 
source and target) were ranked either in decreasing or increasing order. Then CPS of all streams that fell into a particular interval of the ranked temperatures were added and the sum were divided by the temperature difference in that interval to obtain the heat load for that interval. For instance, the heat load $\left(\Delta H_{n}\right)$ for nth interval of temperature difference $\left(\Delta T_{n}\right)$ was determined by

$$
\Delta H_{n}=\left(\sum C P s\right) \times\left(\Delta T_{n}\right)
$$

With the lowest temperature assigned either a zero or an arbitrary heat load, the calculated heat loads were then cumulated over the assigned heat load so that every temperature corresponded to a particular heat load. Finally, the temperatures were then plotted against heat loads to give the composite curves. Now, the combined (i.e. both hot and cold) composite curves for a particular $\Delta T_{M I N}$ produced three distinct regions (Fig. 1). These regions were (1) an overlap region that represented the maximum possible scope of heat recovery within the process, (2) an overshoot of the hot composite curve that represented the minimum cold utility requirement $\left(Q_{C, M I N}\right)$ and (3) an overshoot of the cold composite curve that represented the minimum hot utility requirement $\left(Q_{H, M I N}\right)$.

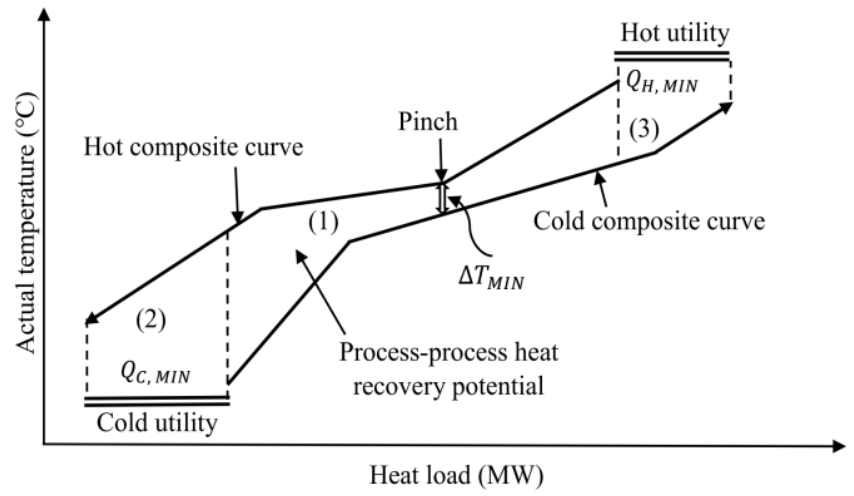

Fig. 1: Combined composite curves

The combined composite curves also gave valuable insights into the selection of appropriate utilities that would provide these heat requirements. The first condition for selection is that the hot utilities must have higher temperatures than the temperatures in the region of the cold composite curve where it will provide heat. Conversely, the cold utilities must have lower temperatures than the temperatures in the region of the hot composite curve where it will receive heat. In conformity with this condition, there were suggested, based on experiences, ranges of the $\Delta T_{M I N}$ for petrochemical industries which should be maintained between the process streams and utility streams (Auta et al., 2012), and this informed the choice of the temperature range for each utility in Table 3 . The second condition is that utility with lower cost is preferable if more than one utility meet the first condition. The choice of annual unit costs was based on information obtained from literatures (Turton et al., 2009; Towler and Sinnott, 2013).

Table 3: Selected utilities (Turton et al., 2009; Auta et al., 2012; Towler and Sinnott, 2013).

\begin{tabular}{|c|c|c|c|c|}
\hline \multirow{2}{*}{ Utility } & \multirow{2}{*}{ Type } & \multicolumn{2}{|c|}{ Temperature $\left({ }^{\circ} \mathrm{C}\right)$} & \multirow{2}{*}{$\begin{array}{l}\text { Unit cost, } C_{U} \\
\text { (\$/MW, year) }\end{array}$} \\
\hline & & Source $\left(T_{S}\right)$ & Target $\left(T_{T}\right)$ & \\
\hline Water (CW) & Cold & 20 & 45 & 11,000 \\
\hline Air (CA) & Cold & 20 & 80 & 5,500 \\
\hline Fuel & Hot & 350 & 400 & 350,000 \\
\hline
\end{tabular}

The grand composite curves were the next to be constructed and the 'Problem Table Method' was also adopted. However, the grand composite curves are different from the combined composite curves in the following senses:

- Both the cold and hot process streams' temperatures were combined together to obtain only one plot.

- Instead of the actual temperatures, the interval temperatures as obtained from Equations (2) were used.

- After obtaining the heat load in each interval using Equation (1), the surplus heat load from one interval to the next down the column of each interval was cascaded and just enough heat was introduced to the top of the cascade to eliminate all the negative values.

- The interval temperatures were then plotted against the cascaded heat loads to give the grand composite curve.

$$
\begin{aligned}
& \text { Hot streams: } T_{I n t}=T_{A c t}-\Delta T_{M I N} / 2 \\
& \text { Cold streams: } T_{I n t}=T_{A c t}+\Delta T_{M I N} / 2
\end{aligned}
$$

where $T_{\text {Act }}$ and $T_{\text {Int }}$ are actual and interval temperatures respectively

The grand composite curves, if correctly constructed would also give the same values of $Q_{C, M I N}$ and $Q_{H, M I N}$ as those obtained from combined composite curves. Next, the pinch point or pinch temperature $\left(T_{P}\right)$ was located while the hot stream pinch $\left(T_{P, h o t}\right)$ and cold stream pinch $\left(T_{P, \text { cold }}\right)$ temperatures were determined. Finally, using the selected utilities, the energy cost targeting for each value of the selected $\Delta T_{M I N}$ was estimated using the following equation (Paiko et al., 2017; Yoro et al., 2018).

$$
C_{E N E R G Y}(\$)=\sum Q_{U} \cdot C_{U}
$$

where $Q_{U}=$ Heat duty of an utility, MW and $C_{U}=$ Unit cost of an utility, \$/MW, year.

\section{2.) Estimation of HEN capital cost targeting}

The capital cost is the heat exchangers' cost, which is a function of the sizes or areas of the heat exchangers. Therefore, the minimum area $\left(A_{M I N}\right)$ targeting was first estimated using the combined composite curves with the utility streams included. It was assumed that the area was evenly distributed between the units since the actual area distribution could not be determined ahead of design. Then the combined composite curves were divided into a set of adjoining sections such that within each section, the hot and cold composite curves did not 
change slope (Fig. 2). This allowed the hot streams in any section, at any point, to exchange heat with the cold streams at the temperature vertically below it (i.e. each section represented one heat exchanger). Here, the heat exchange was assumed to be "vertical" (pure counter-current heat exchange).

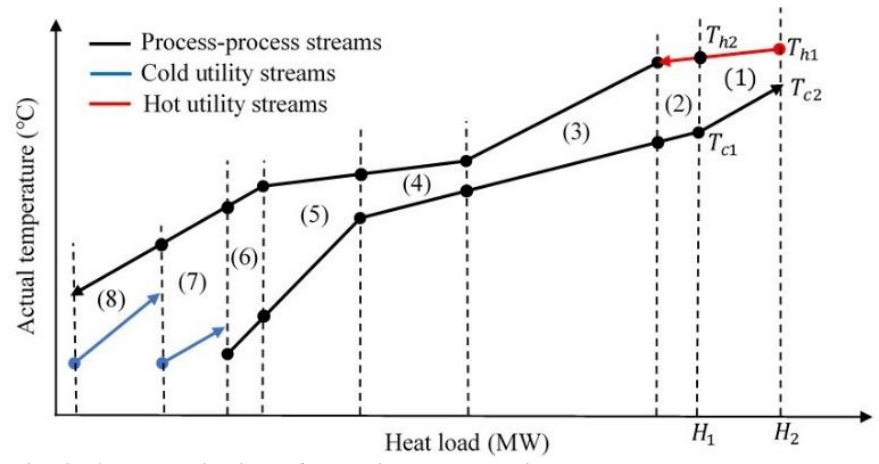

Fig. 2: Area sectioning of combined composite curves.

Therefore, the surface area for each section $\left(A_{i}\right)$ was calculated using the following widely accepted heat exchanger equation defined in Rathjens and Fieg (2019).

$$
A_{i}=\Delta H_{i} /\left(U_{i} \times \Delta T_{L M-i}\right)
$$

where $\Delta H_{i}=$ heat load, $U_{i}=$ Overall heat transfer coefficient as presented in Table 4 (Towler and Sinnott, 2013) and $\Delta T_{L M-i}=\log$ mean temperature difference. Subscript $i$ stands for a particular section.

For example, in section 1 in Figure 2, the heat load $\left(\Delta H_{1}\right)$ and log mean temperature difference $\left(\Delta T_{L M-1}\right)$ were obtained as follows:

$$
\begin{aligned}
& \Delta H_{1}=H_{2}-H_{1} \\
& \Delta T_{L M-1}=\frac{\left(T_{h 1}-T_{c 2}\right)-\left(T_{h 2}-T_{c 1}\right)}{\ln \left[\left(T_{h 1}-T_{c 2}\right) /\left(T_{h 2}-T_{c 1}\right)\right]}
\end{aligned}
$$

Table 4: Selected overall heat transfer coefficients (Towler and Sinnott, 2013).

\begin{tabular}{lc}
\hline Heat exchanging streams & $\begin{array}{c}\text { Overall heat transfer coefficient, } \\
\boldsymbol{U}\left(\mathbf{M W} / \mathbf{m}^{\mathbf{2}}{ }^{\circ} \mathbf{C}\right)\end{array}$ \\
\hline Process stream - Process stream & 250 \\
Process stream - Fuel & 100 \\
Process stream - Cooling water & 500 \\
Process stream - Cooling air & 625 \\
\hline
\end{tabular}

The total area of the HEN $\left(A_{M I N}\right)$ above and below the pinch became equal to the sum of the areas calculated above and below the pinch respectively. That is;

$$
A_{M I N}=\sum A_{i}
$$

It should be noted that the actual $A_{M I N}$ required is generally within $10 \%$ of the area target as calculated using this procedure according to Smith (2005).

Next, the minimum number of units $\left(N_{M I N}\right)$ targeting was separately estimated for sections above and below the pinch. The following equation (Rokni, 2016; Ateeq et al., 2017) was used for each section.

$$
N_{M I N}=N_{H}+N_{C}+N_{U}-1
$$

where $N_{H}=$ Number of hot streams, $N_{C}=$ Number of cold streams and $N_{U}=$ Number of utility streams.

The numbers of hot and cold streams were determined using the $T_{P, \text { hot }}$ and $T_{P, \text { cold }}$ respectively to divide the process streams into two regions (i.e. above the pinch and below the pinch). On the other hand, the number of utility streams depends not only the number of process streams that required the utilities but also on the thermal constraints of the utilities.

Finally, the HEN capital cost $\left(C_{H E N}\right)$ targeting was estimated using the following equation (Paiko et al., 2017; Yoro et al., 2018).

$$
\begin{aligned}
C_{H E N}(\$)= & {\left[N_{M I N}\left\{a+b\left(A_{M I N} / N_{M I N}\right)^{c}\right\}\right]_{A P} } \\
& +\left[N_{M I N}\left\{a+b\left(A_{M I N} / N_{M I N}\right)^{c}\right\}\right]_{B P}
\end{aligned}
$$

Equation (9) was derived from the following wellestablished capital cost of a single heat exchanger equation (Hojjati et al., 2004; Skolpap and Owat, 2018).

$$
\text { Heat Exchanger Cost }(\$)=a+b(\text { Area })^{c}
$$

where $a, b$ and $c$ are known as cost law constants whose values depend on materials of construction among other factors. For a carbon steel shell and tube exchanger which was adopted in this study, the values of these constants are $a=$ 16,000, $b=3,200$ and $c=0.7$ (Linhoff and Vredeveld, 1984; Hojjati et al., 2004). Subscripts $A P$ and $B P$ stand for above the pinch and below the pinch.

\section{3.) Determination of reduction in the total annual cost}

The energy cost targeting $\left(C_{E N E R G Y}\right)$ calculated in section 2.2.1 and the capital cost targeting $\left(C_{H E N}\right)$ calculated in section 2.2.2 were summed to give the total cost targeting $\left(C_{\text {TOTAL }}\right)$. These three costs (i.e. energy, capital and total costs) were then plotted against their respective minimum temperature differences $\left(\Delta T_{M I N}\right)$ on the same graph (presented as Figure 5 in result section). It should be noted that in plotting these data, a regression analysis was used so that lines of best fit were obtained. Because $C_{E N E R G Y}$ increases with increase in $\Delta T_{M I N}$ while $C_{H E N}$ decreases with increase in $\Delta T_{M I N}$, the $C_{T O T A L}$ produces a minimum. The process of determining this minimum is referred to as trade-off between energy cost and capital cost in economic analysis of chemical plants. The 
minimum $C_{\text {TотAL }}$ is known as optimum annual total cost and the minimum temperature difference at which this optimum $C_{\text {TOTAL }}$ is obtained is known as optimum minimum temperature difference (Attarakih et al., 2013; Rokni, 2016; Tibasiima and Okullo, 2017). Next is the determination of existing annual energy cost $\left(C_{E N E R G Y}^{o}\right)$ of the FCC unit which was achieved by applying Equation (3) to the existing utility thermal data. Using the calculated existing $C_{E N E R G Y}^{O}$, the existing total annual cost $\left(C_{\text {TOTAL }}^{o}\right)$ was traced out from the same Figure 5. Finally, the percentage reduction in the total annual cost (\% $C_{\text {TOTAL }}^{R}$ ) of the FCC unit was determined using Equation (11).

$$
\% C_{\text {TOTAL }}^{R}=\frac{C_{\text {TOTAL }}^{O}-C_{\text {TOTAL }}}{C_{\text {TOTAL }}^{o}} \times 100
$$

\section{RESULTS AND DISCUSSION}

\section{A. Presentation of Results}

The results obtained from this work are presented in Figs. 3 to 7 and Tables 5 to 6 .

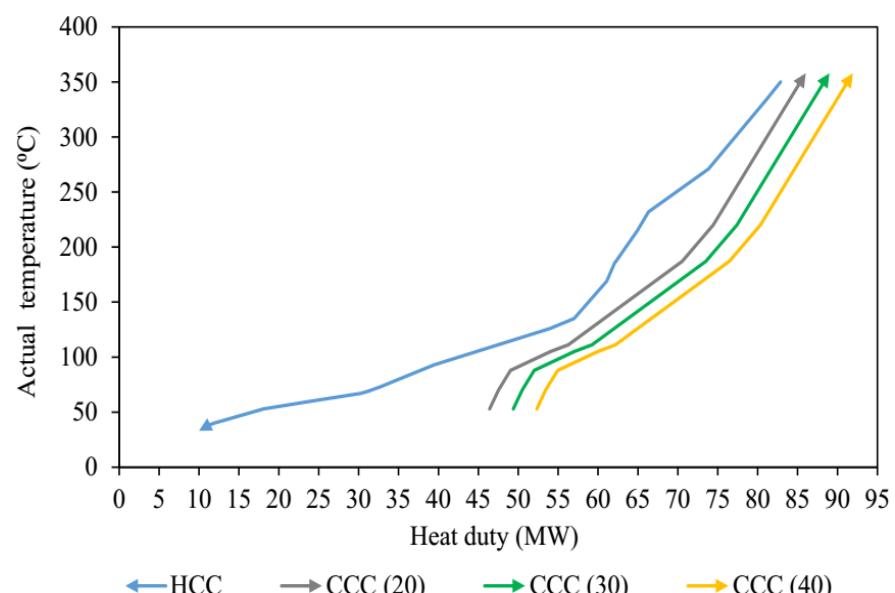

Fig. 3: Combined composite curves for $\Delta T_{M I N}$ of 20,30 and $40^{\circ} \mathrm{C}$.

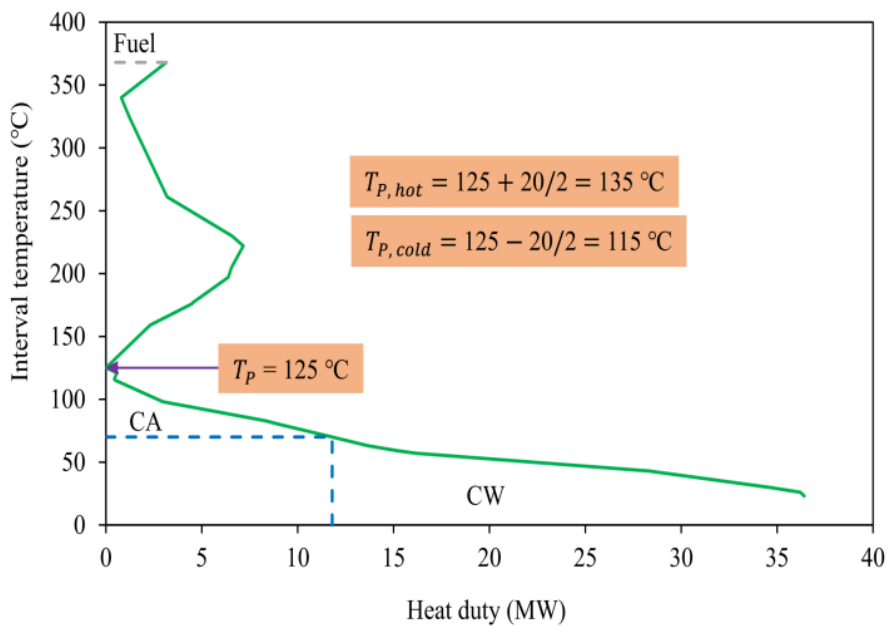

Fig. 4: Grand composite curve for $\Delta T_{M I N}$ of $20^{\circ} \mathrm{C}$.

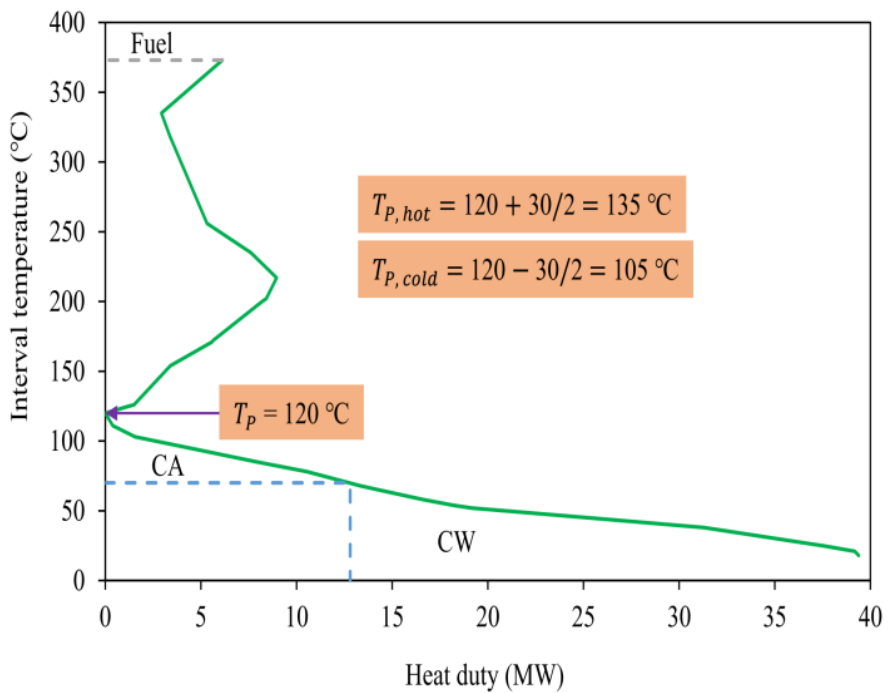

Fig. 5: Grand composite curve for $\Delta T_{M I N}$ of $30^{\circ} \mathrm{C}$.

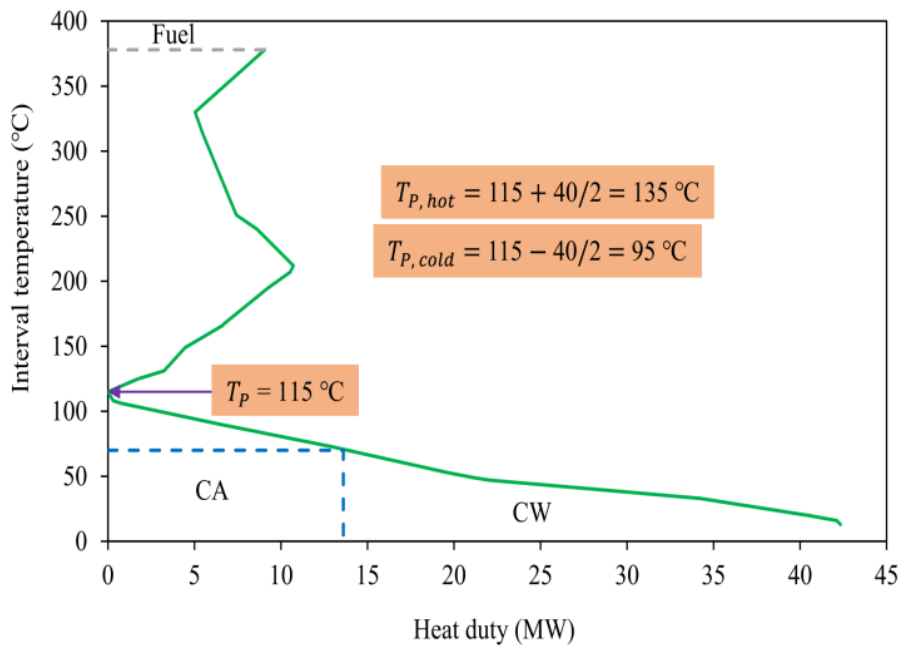

Fig. 6: Grand composite curve for $\Delta T_{M I N}$ of $40^{\circ} \mathrm{C}$.

Table 5: Cost targeting at different $\Delta T_{M I N}$.

\begin{tabular}{|c|c|c|c|c|c|c|}
\hline \multirow[t]{2}{*}{$\begin{array}{c}\Delta T_{M I N} \\
\left({ }^{\circ} \mathrm{C}\right)\end{array}$} & \multicolumn{2}{|c|}{$\begin{array}{c}A_{M I N} \\
\left(\mathbf{m}^{2}\right)\end{array}$} & \multicolumn{2}{|c|}{$N_{M I N}$} & \multirow{2}{*}{$\begin{array}{c}C_{\text {ENERGY }} \\
\text { (Million } \\
\text { \$/Yr.) }\end{array}$} & \multirow{2}{*}{$\begin{array}{c}C_{\text {HEN }} \\
\text { (Million } \\
\text { \$/Yr.) }\end{array}$} \\
\hline & $A P$ & BP & $A P$ & $B P$ & & \\
\hline 5 & 676 & 9827 & 1 & 36 & 0.66 & 6.74 \\
\hline 10 & 678 & 9023 & 1 & 36 & 0.80 & 6.40 \\
\hline 15 & 3770 & 4577 & 9 & 33 & 1.17 & 5.98 \\
\hline 20 & 3302 & 4147 & 9 & 33 & 1.38 & 5.58 \\
\hline 25 & 2688 & 3776 & 12 & 32 & 1.96 & 5.29 \\
\hline 30 & 2765 & 3361 & 10 & 32 & 2.53 & 4.97 \\
\hline 35 & 2643 & 3283 & 10 & 32 & 3.04 & 4.88 \\
\hline 40 & 2594 & 2924 & 10 & 32 & 3.58 & 4.65 \\
\hline
\end{tabular}


Table 6: Annual energy cost of existing HEN.

\begin{tabular}{cccc}
\hline Utility & $\boldsymbol{H}_{\boldsymbol{U}}(\mathbf{M W})$ & $\boldsymbol{C}_{\boldsymbol{U}}(\mathbf{\$} / \mathbf{M W}$, year) & Cost (Million \$/year) \\
\hline $\mathrm{CW}$ & 12.00 & 11000 & 0.132 \\
$\mathrm{CA}$ & 32.88 & 5500 & 0.181 \\
Steam & 2.20 & 250000 & 0.550 \\
Fuel & 9.04 & 350000 & 3.164 \\
\hline$C_{E N E R G Y}^{o}$ & & & 4.027 \\
\hline
\end{tabular}

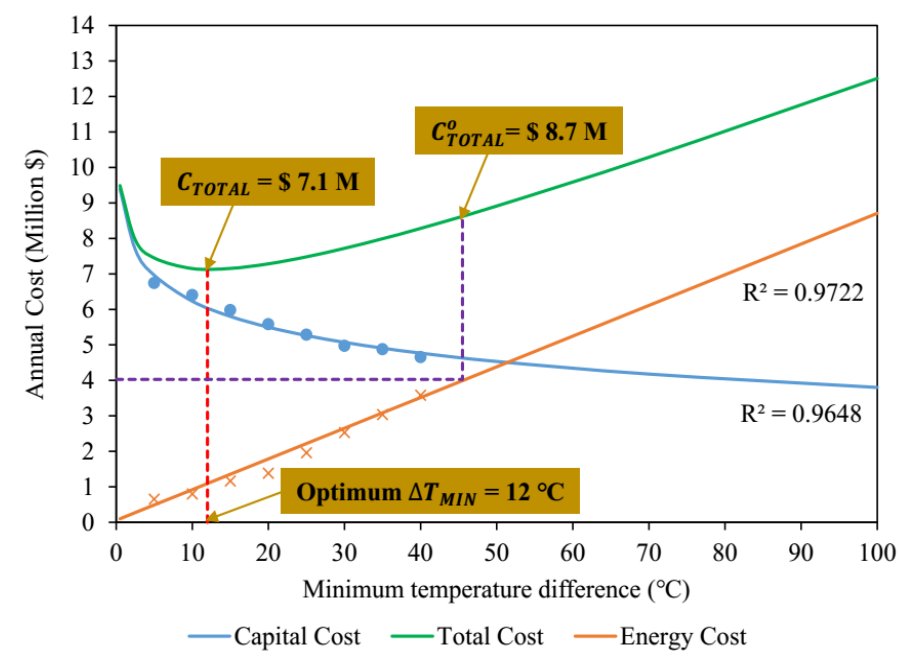

Fig. 7: Energy cost and capital cost trade-off.

\section{B. Discussion of Results}

\section{1.) Combined composite curves}

Hot composite curve (HCC) and some cold composite curves (CCCs) are plotted together as the combined composite curves in Fig. 3. It should be noted that although $\Delta T_{M I N}$ of 5, $10,15,20,25,30,35$ and $40^{\circ} \mathrm{C}$ were used for the analysis, only the composite curves for $\Delta T_{M I N}$ of 20,30 and $40^{\circ} \mathrm{C}$ were presented here for the sake of clarity as they all follow similar trends. The essence of these curves is to find the minimum hot and cold utility requirement. From these curves therefore, the cold utility requirement (the difference between the lowest heat load of the hot composite curve and the lowest heat load of the cold composite curve) was much higher than the hot utility requirement (the difference between the highest heat load of the hot composite curve and the highest heat load of the cold composite curve). Secondly, theses curves show that the higher the $\Delta T_{M I N}$, the higher the hot and cold utility requirements. This is in agreement with what has been reported in the literatures (Smith, 2005; El-Halwagi, 2006).

\section{2.) Grand composite curves}

The grand composite curves for $\Delta T_{M I N}$ of 20,30 and $40^{\circ} \mathrm{C}$ are presented in Figs. 4 to 6 . The reason given in section 3.2.1 regarding the selected values of $\Delta T_{M I N}$ for the composite curves is equally applicable here. These curves show the pinch point, which increased with increase in the $\Delta T_{M I N}$. Again, they also show the hot and the cold pinch points: the hot pinch point remained unchanged while the cold pinch point decreased with increase in the $\Delta T_{M I N}$. These trends are not universal, rather they depend on the nature of the heat exchanger network under consideration. Finally, the cold utility levels shown in these curves were done in such a manner that the cooling water served the coldest portion of the curves up to $70^{\circ} \mathrm{C}$ while the cooling air served the remaining portion. The reason is to make sure that the discharged warm water does not have significant negative impact on the environment (i.e. land or river).

\section{3.) Cost targeting}

Table 5 presents the minimum areas and numbers of units targeting, calculated energy costs, and HEN capital costs for all the initially selected $\Delta T_{M I N}$. It is obvious to see that the total area targeting (i.e. sum of areas above and below the pinch) and the total number of units targeting (i.e. sum of numbers of units above and below the pinch) depended on the $\Delta T_{M I N}$, with the former showing very much stronger dependence. Specifically, the total area targeting decreased with increase in the $\Delta T_{M I N}$. This is expected because the larger the $\Delta T_{M I N}$, the less the amount of heat that can be exchanged between cold and hot process streams. In contrast, the total minimum number of unit targeting showed slight increase from 37 at $\Delta T_{M I N}$ of 5 and $10^{\circ} \mathrm{C}$ to 42 at higher $\Delta T_{M I N}$.

Regarding the cost targeting, the trend in the total area targeting translated to having higher hot and cold utility requirements which was why the energy cost targeting also increased with the increase in the $\Delta T_{M I N}$. It should be noted that the energy cost depends only on the quantity and type of utilities based on Equation (3) and not the number of heat exchangers or units. On the other hand, the HEN cost is proportional to both the area and the number of units based on Equation (9). Therefore, since the trend of the total area targeting with respect to the $\Delta T_{M I N}$ was in contrast with that of the total minimum number of unit targeting, then the overall trend of HEN capital cost targeting with respect to the $\Delta T_{M I N}$ would depend on the relative dominance of the area and the number of units. As can be seen in Table 5, the HEN capital cost targeting decreased with increase in the $\Delta T_{M I N}$ showing that the effect of the area on HEN cost outweighed that of the number of units.

\section{4.) Reduction in total annual cost}

The annual energy cost of the existing HEN was calculated, and the result is presented in Table 6 . Using the energy cost and capital cost trade-off diagram presented in Figure 7 , the existing total annual cost was found to be $\$ 8.7$ Million. The total annual cost targeting ( $\$ 7.1$ Million) is the minimum total annual cost in Fig. 7 and the temperature $\left(12^{\circ} \mathrm{C}\right)$ at which this is obtained is called the optimum minimum temperature difference (optimum $\Delta T_{M I N}$ ). Using Equation (11), the percentage reduction in the total annual cost was obtained to be $18.4 \%$. This means that if the design of the HEN for FCC unit was done using the optimum $\Delta T_{M I N}, 18.4 \%$ of the total cost, which translated to about $\$ 1.6$ Million, would have been be saved annually.

\section{CONCLUSION}

Pinch technology was used to determine the reduction in the total annual cost of HEN of FCC unit and the following conclusions were drawn from the results. 
a) The total annual cost of the existing design of the FCC unit was found to $\$ 8.7$ Million.

b) The optimum minimum temperature difference of the FCC unit was found to be $12^{\circ} \mathrm{C}$.

c) The total annual cost if the optimum minimum temperature difference was used to design the FCC unit was found to be $\$ 7.1$ Million.

d) The percentage reduction in the total annual cost using optimum minimum temperature difference was found to be $18.4 \%$.

\section{ACKNOWLEDGEMENT}

My sincere appreciations go to the management of Kaduna Refining and Petrochemical Company (KRPC), Kaduna for giving unhindered assess to the operating manual of the FCC unit from which the relevant operating data were extracted.

\section{REFERENCES}

Abdul Aziz, E.; S. R. Wan Alwi; J. S. Lim; Z. Abdul Manan and J. J. Klemes. (2017). An integrated Pinch Analysis Framework for Low $\mathrm{CO}_{2}$ Emissions Industrial Site Planning. Journal of Cleaner Production, 146: 125 - 138.

Adejoh A. Z.; D. F. Aloko and I. J. Muhammad. (2013). Energy Integration of Vacuum Distillation Plant Technology. Advances in Applied Science Research, 264 - 265.

Aguitoni, M. C.; L. V. Pavão; P. H. Siqueira; L. Jiménez and M. A. S. S. Ravagnani. (2018). Synthesis of a CostOptimal Heat Exchanger Network Using Genetic Algorithm and Differential Evolution. Chemical Engineering Transactions, 70: $979-984$.

Akgun, N. and Ozcelik, Z. (2017). Debottlenecking and Retrofitting by Pinch Analysis in a Chemical Plant. American Journal of Energy Engineering, 5(5): $39-49$.

Akpa J. G.; R. I. Uzono and K. K. Dagde. (2018). Energy Integration of Butene-1 Production Plant Using Pinch Technology. International Journal of Energy and Environmental Research, 7(1): $1-17$.

Anastasovski, A.; P. Rašković and Z. Guzović. (2017). Design and Analysis of Heat Recovery System in Bioprocess Plant. Energy Conversion and Management, 104: 32 - 43.

Anna G. (2011). Pinch Analysis of Nynas Refinery. Master Thesis, Chalmers University of Technology, Sweden.

Ateeq, A. A.; M. A. Taher and F. A. Al-Salam. (2017). Energy Saving in Atmospheric Distillation Unit by Retrofit Design of Heat Exchanger Networks of Al-Basra Refinery. International Journal of Engineering Research and Technology, 6(4): $425-430$.

Attarakih, M.; M. Abu-Khader; T. Saieq and H. Bart. (2013). Ethane Production Plant for Better Energy Integration and Cost Reduction in Jordan. Journal of Chemical Technology and Engineering, 48(3): 265 - 276.

Auta, M.; A. S. Ahmed and H. F. Akande. (2012). Comparative Studies of Traditional (Non-Energy Integration) and Energy Integration of Catalytic Reforming Unit Using Pinch Analysis. Nigerian Journal of Technological Development, 9(1): 1-10.
Barambu, N. U.; U. A. El-Nafaty and I. A. Saeed. (2017). Energy Integration of Sugar Production Plant Using Pinch Analysis: A Case Study of Savanah Sugar Company Yola, Nigeria. Advances in Applied Science Research, 8(2):20 - 29.

Chang, C.; X. Chen; Y. Wang and X. Feng. (2017). Simultaneous Optimization of Multi-Plant Heat Integration Using Intermediate Fluid Circles. Energy, 121: 306 - 317.

Dezhen, C.; S. Yang; X. Luo; Q. Wen and H. Ma. (2007). An Explicit Solution for Thermal Calculation and Synthesis of Superstructure Heat Exchanger Networks. Chinese Journal of Chemical Engineering, 15: 296 -301 .

El-Halwagi, M. M. (2006). Process Integration. Academic Press Publisher, Cambridge, Boston, USA.

Gunderson, T. and Naess, L. (1988). The Synthesis of Cost Optimal Heat Exchanger Network: An Industrial Review. Computers and Chemical Engineering, 12: 503 - 530.

Hallale, N. and Fraser, D. M. (2000). Capital and Total Cost Targets for Mass Exchange Networks, Part 2: Detailed Capital Cost Models, Computer and Chemical Engineering, 23: $1681-1699$.

Hojjati, M. R.; M. R. Omidkhah and M. H. Panjeh Shahi. (2004). Cost Effective Heat Exchanger Network Design with Mixed Materials of Construction. Iranian Journal of Chemical Engineering, 23(2): 89 - 100.

Leni C. E.; D. G. Mark; G. Ferdinand and G. Nurak. (2015). Brewery Heat Exchanger Networks Design and Optimization Based on Pinch Analysis at a Single $\Delta \mathrm{T}_{\min }$. Philippine Engineering Journal, 36(1): $54-75$.

Li, Z.; X. Jia; D. C. Y. Foo and R. R. Tan. (2016). Minimizing Carbon Footprint Using Pinch Analysis: The Case of Regional Renewable Electricity Planning in China. Applied Energy, 184: 1051 - 1062.

Linnhoff, B. and Hindmarsh, E. (1983). The Pinch Design Method for Heat Exchanger Networks. Chemical Engineering Science. 38: 745 -763.

Linnhoff, B. and Vredeveld, D. R. (1984). Pinch Technology Has Come of Age. Chemical Engineering Progress, 80(7): $33-40$.

Lukman, Y.; B. Suleiman and O. S. Azeez. (2016). Evaluation of Total Annual Costs of Heat Exchanger Networks Using Modified Pinch Analysis. Nigerian Journal of Technology (NIJOTECH), 35(3): 537 - 543.

Lukman, Y.; B. Suleiman; B. and O. S. Azeez. (2015). Analysis of Heat Exchanger Networks for Minimum Total Annual Cost Using Pinch Analysis. Paper presented at International Engineering Conference, $1-7$, Federal University of Technology Minna, Nigeria.

Manan, Z.A.; W. N. R. Mohd Nawi; S. R. Wan Alwi and J. J. Klemes. (2017). Advances in Process Integration Research for $\mathrm{CO} 2$ Emission Reduction: A review. Journal of Cleaner Production, 167: 1 - 13.

Marton, S.; E. Svensson; R. Subiaco; F. Bengtsson and S. Harvey. (2017). A Steam Utility Network Model for the Evaluation of Heat Integration Retrofits - A Case Study of an Oil Refinery. Journal of Sustainable Development of Energy, Water and Environment Systems, 5(4): 560 - 578. 
Olakunle, M. S. and Abubakar, A. (2011). Heat Integration of Fluid Catalytic Cracking (FCC) Unit Using Pinch Analysis - A Case Study of Kaduna Refining and Petrochemical Company FCC Unit. Nigerian Journal of Engineering, 18(1): $40-46$.

Paiko, I. I.; O. S. Azeez; N. Makwashi and D. Zhao. (2017). Pinch Analysis in Optimising Energy Consumption on a Naphtha Hydrotreating Unit in a Refinery. Petroleum \& Petrochemical Engineering Journal, 1(5): 000126.

Pritam S. R.; S. Bandyopadhyay; D. C. Y. Foo; R. R. Tan and V. Kazantzi. (2017). A pinch Analysis Approach to Project Selection Problem. Paper presented in 6th International Symposium on Advanced Control of Industrial Processes (AdCONIP), 49 - 54, Taipei, Taiwan.

Rathjens, M. and Fieg, G. (2018). Design of CostOptimal Heat Exchanger Networks Considering Individual, Match-Dependent Cost Functions. Chemical Engineering Transactions, 70: $601-606$.

Rathjens, M. and Fieg, G. (2019). Cost-Optimal Heat Exchanger Network Synthesis Based on a Flexible Cost Functions Framework. Energies, 12(784): 1 - 17.

Rathjens, M.; T. Bohnenstädt; G. Fieg and O. Engel. (2016). Synthesis of Heat Exchanger Networks Taking into Account Cost and Dynamic Considerations. Procedia Engineering, 157: $341-348$.

Rokni, M. (2016). Introduction to Pinch Technology. Report, Technical University of Denmark (DTU), Kongens Lyngby, Demark.

Sasikala, R. (2017). Water and Wastewater Optimization in Multiple Contaminants Network Using Water Pinch Technology. International Journal of Research Granthaalayah, 5(8:SE): $1-7$.

Skolpap, W. and Owa, N. (2018). Pinch Analysis of a Commercial-Scale Sugarcane Wax Accelerated-Solvent Extraction and Purification Process. The International Journal of Engineering and Science, 7(7): 25-34.

Smith, R. (2005). Chemical process design and integration. John Wiley \& Sons Ltd, England.
Souza, R. D.; S. Khanam and B. Mohanty. (2016). Synthesis of Heat Exchanger Network Considering Pressure Drop and Layout of Equipment Exchanging Heat. Energy, 101: $484-495$.

Tibasiima, N. and Okullo, A. (2017). Energy Targeting for a Brewing Process Using Pinch Analysis, Energy and Power Engineering, 2017, 9, $11-21$.

Towler, G. and Sinnott, R. (2013). Chemical Engineering Design: Principles, Practice and Economics of Plant and Process Design, 2nd Edition, Butterworth-Heinemann publications, 225 Wyman Street, Waltham, MA 02451, USA.

Turton, R.; R. C. Bailie; W. B. Whiting and J. A. Shaeiwitz. (2009). Analysis, Synthesis, and Design of Chemical Processes, 3rd Edition, Prentice Hall, Upper Saddle River, New Jersey, United State.

Ulyev, L.; M. Vasiliev and S. Boldyryev. (2018). Process Integration of Crude Oil Distillation with Technological and Economic Restrictions. Journal of Environmental Management, 222: $454-464$.

Venkatesh, G. (2019). Pinch Analysis, as a Technique for Optimising Resource Utilisation and Promoting Environmental Sustainability: A Review of Recent Case Studies from the Developing World and Transition Economies. Resources Environment and Information Engineering, 1(1): 1-17.

Verma, S. and Kumar, S. Y. (2017). Process Integration Using Pinch Analysis: A Cement Industry Case Study. International Journal of Applied Engineering Research, 12(24): 14760 - 14763.

Yoro, K. O.; A. J. Isafade and M. O. Daramola. (2018). Sequential Synthesis of Mass Exchanger Networks for $\mathrm{CO}_{2}$ Capture. Paper Presented at World Congress on Engineering and Computer Science, 503 - 508, San Francisco, USA.

Yoro, K. O.; P. T. Sekoai; A. J. Isafade and M. O. Daramola. (2019). A Review on Heat and Mass Integration Techniques for Energy and Material Minimization during $\mathrm{CO}_{2}$ Capture. International Journal of Energy and Environmental Engineering, 10(3): 367-387. 